\title{
Hypoglycemia due to an adult-onset nesidioblastosis, a diagnostic and management dilemma
}

\author{
Mohammed Qintar, Firas Sibai ${ }^{1}$, Mohammad Taha ${ }^{1}$
}

Internal Medicine Department, Cleveland Clinic Foundation, Cleveland, $\mathrm{OH},{ }^{1}$ Internal Medicine Department, University of Kansas Medical Center, Kansas City, KS

\begin{tabular}{|c|}
\hline Access this article online \\
\hline Website: www.avicennajmed.com \\
\hline DOI: 10.4103/2231-0770.99164 \\
\hline Quick Response Code: \\
\hline
\end{tabular}

\section{ABSTRACT}

We describe a case of a 40 year old patient with recurrent severe fasting and postprandial symptomatic hypoglycemia that occurred 6 years after gastric bypass surgery. The hypoglycemia was associated with increased insulin and $\mathrm{C}$ peptide but all diagnostic modalities for localizing an insulinoma were negative. Medical management failed to control symptoms and the patient underwent subtotal pancreatectomy. Surgical tissue examination confirmed the diagnosis of noninsulinoma pancreatogenous hypoglycaemia syndrome (NIPHS) or nesidioblastosis. Initially after surgery the patient had full remission but after 6 months hypoglycemia recurred. However, this time it was well-controlled with octreotide treatment.

Key words: Hypoglycemia, nesidioblastosis, gastric bypass surgery, noninsulinoma pancreatogenous hypoglycaemia syndrome, NIPHS

\section{INTRODUCTION}

Hypoglycemia not caused by diabetes mellitus treatment is uncommon and can present diagnostic and management challenges. ${ }^{[1]}$ The majority of hyperinsulinemic hypoglycemia cases are caused by insulinoma and only less than $5 \%$ are caused by noninsulinoma pancreatogenous hypoglycaemia syndrome (NIPHS) or nesidioblastosis. ${ }^{[2,3]}$ Here we report a case of uncontrolled symptomatic hypoglycemia due to nesidioblastosis in a patient with history of gastric bypass surgery. The patient failed medical management and had to undergo subtotal pancreatectomy.

\section{CASE REPORT}

Our patient is a 40 year old female with past medical history of morbid obesity who underwent Roux-en-Y gastric bypass for weight reduction purposes 6 years before presentation. The patient had no major complications after surgery and no alcohol or drug use. She presented to our hospital with recurrent right upper quadrant pain, nausea and vomiting, and was found to have blood glucose of $15 \mathrm{mg} / \mathrm{dl}$ during an episode of dizziness, diaphoresis, and weakness. These symptoms resolved with dextrose solution administration; however, the patient had multiple similar episodes of both fasting and post-prandial symptomatic hypoglycemia that required starting dextrose solution drip. She was never diagnosed with diabetes and denied taking insulin or oral hypoglycemic medications. Upon further questioning, she admitted having similar episodes at home. During one of the fasting hypoglycemic episodes, glucose, insulin, and C-peptide levels were $25 \mathrm{mg} / \mathrm{dl}$ (normal range: 70- 100), $153.0 \mathrm{mcu} / \mathrm{ml}$ (normal range: $2-23$ ), and $13 \mathrm{ng} / \mathrm{ml}$ (normal range: 0.9-4.3), respectively. Insulin antibodies were negative. Urine sulfonylurea screen was negative. The patient was diagnosed with endogenous hyperinsulinemic hypoglycemia (insulinoma versus nesidioblastosis). Other endocrine disorders that can cause hypoglycemia, such as hypothyroidism and adrenal insufficiency, were ruled out.

To differentiate between insulinoma and nesidioblastosis, abdominal CT scan and endoscopic ultrasound were performed but failed to detect a pancreatic mass. An octreotide scan was done and did not show focal abnormality to suggest insulinoma -the test used radiolabeled somatostatin analogs to detect neuroendocrine tumors like insulinoma that have receptors for somatostatin-. Another specialized test called selective arterial calcium stimulated pancreatic venous 
sampling (SACST) was done to help localize the area(s) of the pancreas that was over-secreting insulin; this test uses calcium gluconate injections, an insulin secretagogue, into arteries supplying the pancreas with subsequent sampling of the hepatic vein to test for insulin. The SACST revealed a 6-fold increase for the superior mesenteric artery injection compared with a 3-fold increase for the splenic artery. The hepatic artery injection produced no change. Based on the results insulinoma was less likely because the increase of insulin secretion was reported in two different pancreatic artery injections. This diffuse pattern of insulin secretion favors nesidioblastosis.

The patient was started on octreotide $50 \mathrm{mg}$ injections in order to control hypoglycemia; it was titrated up to $300 \mathrm{mg}$ three times daily without much improvement. She was tried on diazoxide, but it was discontinued due to side effects of fluid retention and nausea. The patient was also started on nefidipine. Despite these medical therapies, she continued to have recurrent symptomatic hypoglycemia.

Since none of the imaging studies showed focal lesion(s), and the patient failed medical management, she underwent subtotal $80 \%$ distal pancreatectomy.

Histopathology examination of the excised pancreatic tissues showed diffuse islet cells hypertrophy, Islet cell pleomorphism and Ductal insular complex. These features are typical for nesidioblastosis [Figures 1-3].

Our patient did well postoperatively and was hypoglycemia free for about six months, but her hypoglycemic episodes recurred. She then responded well to medical therapy with octreotide subcutaneous injections with close follow ups.

\section{DISCUSSION}

Nesidioblastosis was first reported in infants by George F. Laidlaw in 1938. ${ }^{[4]} \mathrm{He}$ described nesidioblastosis as neoformation of Langerhans islets from the pancreatic ductal epithelium, and it is now known to be the primary cause of persistent hyperinsulinemic hypoglycemia in infants. ${ }^{[5]}$ In Adults, hyperinsulinemic hypoglycemia is mainly caused by insulinomas, other causes are rare and usually due to adult-onset nesidioblastosis, which was first described in 1975. ${ }^{[6]}$ Since then fewer than 100 cases have been reported but it seems to be increasing in frequency. ${ }^{[7]}$

The cause of adult-onset nesidioblastosis is unknown, but there seems to be an association with gastric bypass surgery. ${ }^{[8]}$ Our patient underwent gastric bypass surgery about 6 years before presentation. The distinction between insulinoma and nesidioblastosis preoperatively can sometimes be difficult as the clinical presentation might be

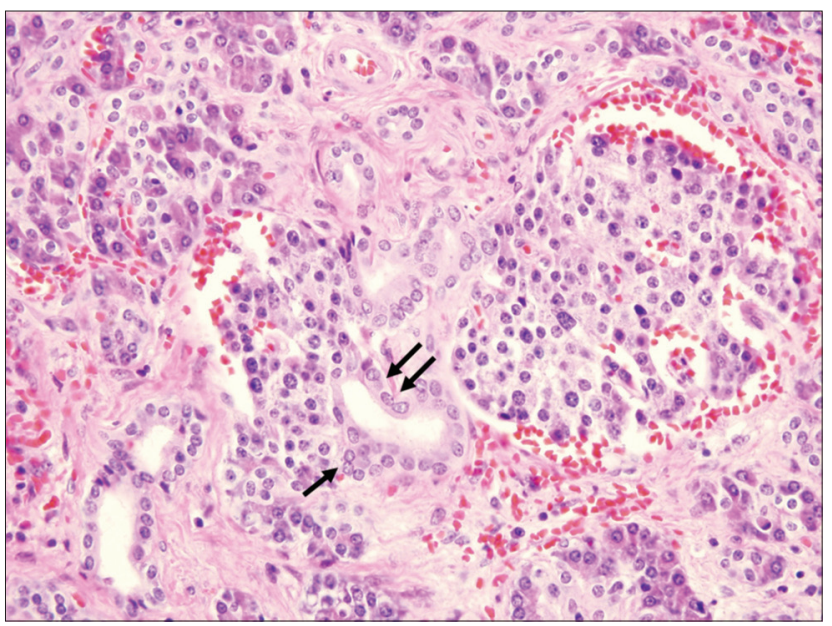

Figure 1: Ductal insular complex. Islet cells (single arrow) entering into the duct (double arrows) $(\times 40)$

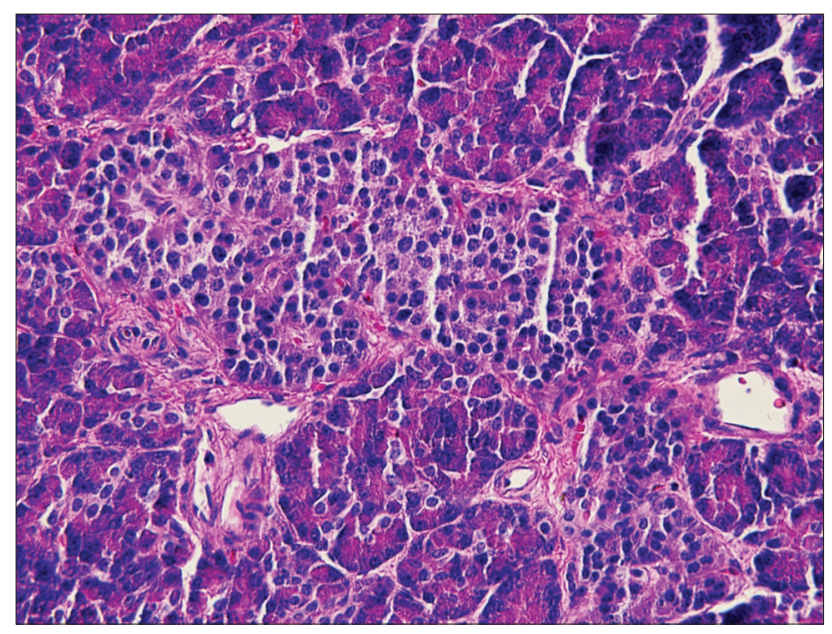

Figure 2: Irregular shaped hypertrophied islets $(\times 40)$

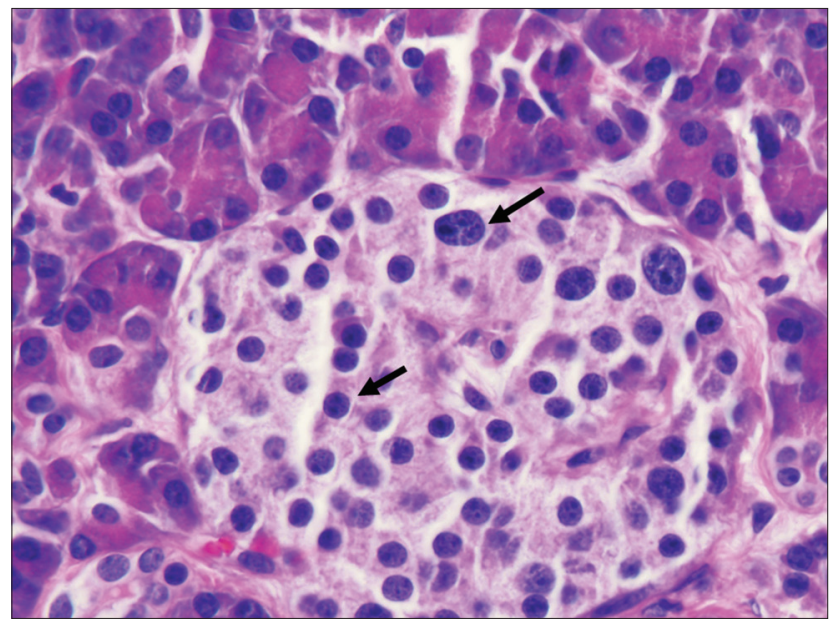

Figure 3: Islet cell pleomorphism. Marked difference in size of cells within same islet $(\times 100)$

similar, and imaging studies can be equivocal. ${ }^{[1,9]}$ In patient with nesidioblastosis symptoms occur mainly postprandially and only rarely while fasting. In contrast, most patients 
with insulinomas have fasting hypoglycemia. ${ }^{[2,8]}$ Moreover, radiological localization studies, such as $\mathrm{CT}$ scan, endoscopic ultrasound, octreotide scan, and selective arterial calcium stimulation test (SACST) with hepatic venous sampling, can be performed to distinguish between a focal abnormality (insulinoma) and a diffuse process (nesidioblastosis).

Other possible etiologies of hyperinsulinemic hypoglycemia include drug induced hypoglycemia, gastric dumping syndrome and exogenous insulin administration. Our patient had both fasting and post-prandial symptomatic hypoglycemia. We have documented inappropriately high insulin levels while hypoglycemic during fasting periods, which goes against dumping syndrome. Drug induced hypoglycemia was considered and ruled out by urine screening for Sulfonylurea. In addition High C-peptide levels seen in our patient should not be seen with exogenous insulin administration.

The patient was tried on aggressive medical therapy including Octreotide injections (to suppress the secretion of insulin), Diazoxide (a potassium channel blocker that can decrease insulin secretion), and Nifedipine (a calcium channel blocker that can decrease insulin secretion). Despite this medical management, the patient continued to have symptomatic hypoglycemia. Since medical management deemed ineffective, she underwent subtotal $80 \%$ distal pancreatectomy.

Although there is limited data regarding the efficacy of pancreatectomy for nesidioblastosis, successful resolution of hypoglycemia has been reported after partial or subtotal pancreatectomy. ${ }^{[10]}$ On the other hand, recurrent hypoglycemia has also been reported that may require total pancreatectomy. ${ }^{[11]}$

Histopathology descriptions of excised pancreatic tissue include islet cell hypertrophy with enlarged and hyperchromatic nuclei, increased periductular islets , and $\beta$-cells budding off ductular epithelium. ${ }^{[12,13]}$

\section{CONCLUSION}

Adult-onset nesidioblastosis is the main cause of noninsulinoma hyperinsulinemic hypoglycaemia and should be considered in patients with previous history of gastric bypass surgery; subtotal distal pancreatectomy could provide clinical benefit in refractory cases.

\section{REFERENCES}

1. Ng CL: Hypoglycemia in nondiabetic patients - an evidence. Aust Fam Physician 2010;39:399-404.

2. Jabri AL, Bayard C: Nesidioblastosis associated with hyperinsulinemic hypoglycemia in adults: Review of the literature. Eur J Intern Med 2004;15:407-10.

3. Fajans SS, Vinik AI. Insulin-producing islet cell tumors. Endocrinol Metab Clin North Am 1989;18:45-74.

4. Laidlaw GF. Nesidioblastoma, the islet tumor of the pancreas. Am J Pathol 1938;14:125-134.5.

5. de Lonlay-Debeney P, Poggi-Travert F, Fournet JC, Sempoux C, Vici CD, Brunelle $\mathrm{F}$, et al. Clinical features of 52 neonates with hyperinsulinism. N Engl J Med 1999;340:1169-75.

6. Albers, N, Löhr M, Bogner U, Loy V, Klöppel G. Nesidioblastosis of the pancreas in an adult with persistent hyperinsulinemic hypoglycemia. Am J Clin Pathol 1989;91:336-40.

7. Manson JE, Skerrett PJ, Greenland P, Vanltallie TB. The escalating pandemics of obesity and sedentary lifestyle: A call to action for clinicians. Arch Intern Med 2004;164:249-58.

8. McLaughlin T, Peck M, Holst J, Deacon C. Reversible hyperinsulinemic hypoglycemia after gastric bypass: A consequence of altered nutrient delivery. J Clin Endocrinol Metab 2010;95:1851-5. Epub 2010 Feb 4.

9. Starke A, Saddig C, Kirch B, Tschahargane C, Goretzki P. Islet hyperplasia in adults: Challenge to preoperatively diagnose non-insulinoma pancreatogenic hypoglycemia syndrome. World J Surg 2006;30:670-9.

10. Thompson GB, Service FJ, Andrews JC, Lloyd RV, Natt N, van Heerden JA, et al. Noninsulinoma pancreatogenous hypoglycemia syndrome: An update in 10 surgically treated patients. Surgery 2000;128:937-44; discussion 944-5.

11. Clancy TE, Moore FD Jr, Zinner MJ. Post-gastric bypass hyperinsulinism with nesidioblastosis: Subtotal or total pancreatectomy may be needed to prevent recurrent hypoglycemia. J Gastrointest Surg 2006;10: 1116-9.

12. Anlauf M, Wieben D, Perren A, Sipos B, Komminoth P, Raffel A, et al. Persistent hyperinsulinemic hypoglycemia in 15 adults with diffuse nesidioblastosis: Diagnostic criteria, incidence, and characterization of beta-cell changes. Am J Surg Pathol 2005;29:524-33.

13. Service FJ, Natt N, Thompson GB, Grant CS, van Heerden JA, Andrews JC, et al. Noninsulinoma pancreatogenous hypoglycemia: A novel syndrome of hyperinsulinemic hypoglycemia in adults independent of mutations in Kir6.2 and SUR1 genes. J Clin Endocrinol Metab 1999;84:1582-9.

Cite this article as: Qintar M, Sibai F, Taha M. Hypoglycemia due to an adultonset nesidioblastosis, a diagnostic and management dilemma. Avicenna J Med 2012;2:45-7.

Source of Support: Nil, Conflict of Interest: None declared. 